
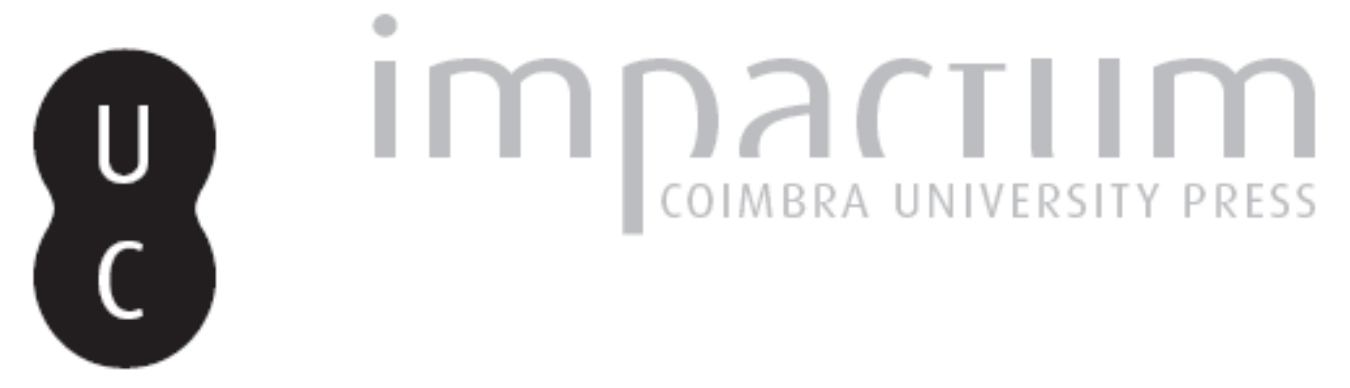

\title{
[Recensão a] Histoire et Archéologie de la Péninsule Ibérique Antique. Chroniques Quinquennales, 1968-1987
}
Autor(es):
D’Encarnaçâo, José

Publicado por: Imprensa da Universidade de Coimbra

URL persistente:

URI:http://hdl.handle.net/10316.2/45420

DOI:

DOI:https://dx.doi.org/10.14195/1647-8657_37_18

Accessed : $\quad$ 26-Apr-2023 10:09:21

A navegação consulta e descarregamento dos títulos inseridos nas Bibliotecas Digitais UC Digitalis, UC Pombalina e UC Impactum, pressupõem a aceitação plena e sem reservas dos Termos e Condições de Uso destas Bibliotecas Digitais, disponíveis em https://digitalis.uc.pt/pt-pt/termos.

Conforme exposto nos referidos Termos e Condições de Uso, o descarregamento de títulos de acesso restrito requer uma licença válida de autorização devendo o utilizador aceder ao(s) documento(s) a partir de um endereço de IP da instituição detentora da supramencionada licença.

Ao utilizador é apenas permitido o descarregamento para uso pessoal, pelo que o emprego do(s) título(s) descarregado(s) para outro fim, designadamente comercial, carece de autorização do respetivo autor ou editor da obra.

Na medida em que todas as obras da UC Digitalis se encontram protegidas pelo Código do Direito de Autor e Direitos Conexos e demais legislação aplicável, toda a cópia, parcial ou total, deste documento, nos casos em que é legalmente admitida, deverá conter ou fazer-se acompanhar por este aviso.

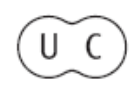


UNIVERSIDADE DE COIMBRA

FACULDADE DE LETRAS

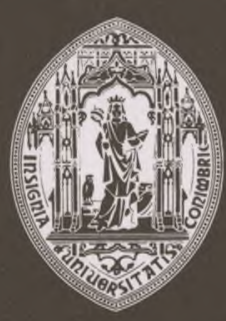

\section{CONIMBRIGA}

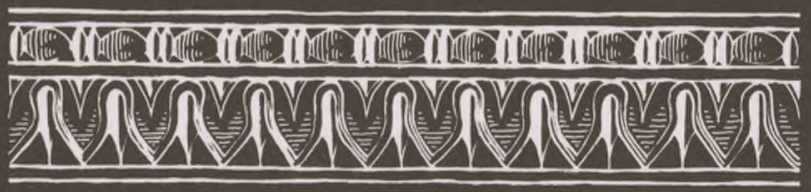

VOLUME XXXVII - 1998 
Vejamos, perfeitamente ao acaso, uma inscrição estudada num e noutro lado: o epitáfio de Caecilia Primitiva, de Valência ( ${ }^{\circ} 50 \mathrm{em}$ ambos os corpora). A leitura é a mesma; as dimensões diferem, no que concerne à espessura (36 e 39); o rol bibliográfico é mais extenso em Corell. Mas a sequência de apresentação dos textos não é a mesma, tanto que o $\mathrm{n}^{\circ} 66$ de Corell é CILII²/14 36 e, aqui, já há diferentes leituras do gentilicio da dedicante - Lettia (CIL) e Leteia (Corell).

Voltemos à análise de $\mathrm{CIL}^{2} / 14$.

$\mathrm{O}$ esquema de cada ficha - redigida em latim - é idêntico ao que se adoptara no século XIX: número identificativo seguido do tipo de inscrição, breve descrição do monumento, local de achado e paradeiro, leitura interpretada, bibliografia, variantes de leitura e sucinto comentário. Traz cada uma, em iniciais, a identificação do responsável pela sua elaboração.

Como já assinalei em relação ao fascículo dedicado ao conventus Cordubensis, trata-se, também aqui - e, inclusive, pelas razões que deixamos transparecer - de um instrumento de trabalho doravante imprescindível, cuja verdadeira utilidade os índices sobremaneira virão potenciar e será com o uso que os dados ora apresentados irão suscitando outras problemáticas.

Estamos, não há dúvida, perante uma epigrafia predominantemente urbana; vemo-lo na tipologia dos monumentos (aras, placas, inscrições monumentais), na onomástica das personagens (raro parece ser o traço de indigenismo e frequente a antroponimia de raiz grega, a indiciar a presença de libertos). É, mesmo sem análises de pormenor, uma epigrafia datável, em larga percentagem, dos primórdios da ocupação romana peninsular: vejam-se as estelas de topo arredondado (v. g., nos 240, 415, 522 e 642), a gravação por meio de goiva $\left(n^{\circ} 779\right)$, a ausência de cognomen $\left(n^{\circ} 433\right)$ e, a ajuizar pelas fotografias apresentadas, a ausência também de elementos decorativos.

JosÉ D’ENCARNAÇÂO

Histoire et Archéologie de la Péninsule Ibérique Antique. Chroniques Quinquennales, 1968-1987. Publications du Centre Pierre Paris (UA 99 1), $\mathrm{n}^{\circ} 24$. Diffusion de Boccard, Paris, 1993. 644 pp.

Editado por Robert Étienne e por Françoise May et, com a colaboração de Isabelle Morand, inclui este volume as crónicas bibliográficas que, desde 1968, os investigadores do Centre Pierre Paris foram efectuando e oportunamente se publicaram na Revue des Études Anciennes.

Como unidade de investigação do CNRS na Universidade de Bordéus III, no Conimbriga, 37 (1998) 267-310 
âmbito da Arqueologia e da História Antiga, este Centro, depois de um período em que o Norte de África reclamou o seu interesse (recorde-se a publicação de Robert Etienne e Georges Fabre sobre o cemitério dos officiales de Cartago - in Recherches sur les Structures Sociales dans VAntiquité Classique, Paris, 1970, 81-97 - ou urna monografia sobre Vollubilis da autoria de R. Étienne - Le Quartier Nord-Est de Volubilis, Paris, 1960 - ou, ainda, o trabalho de A. Jodin também sobre a Volubilis pré-cláudia), voltou as suas atenções, na década de 60, para a Historia Antiga peninsular, na sequência, aliás, do interesse a ela votado pelo seu patrono Pierre Paris (L'Espagne de 1895 et 1897, Journal de Voyage, Paris, 1979).

Em Portugal, foram encetadas escavações em Conimbriga, um projecto luso-francês; em Espanha, houve trabalhos arqueológicos em Baelo, para me referir apenas a um dos mais relevantes, e missões "epigráficas" a Mérida (cujo resultado não viu ainda a luz do dia), a Lugo (E Arias Vilas, P Le Roux e A. Tranoy, Inscriptions de la Province de Lugo, Paris, 1979), à região da Catalunha (de que resultaram os três primeiros volumes das Inscriptions Romaines de Catalogne, Paris, 1984, 1986 e 1991, da responsabilidade de Georges Fabre, Marcos Mayer e Isabel Rodà).

Foi também no âmbito dessa colaboração que boa parte desses investigadores acabaram por fazer, sobre temática hispânica, as respectivas teses de doutoramento, a exemplo do volume clássico, de Robert Étienne, sobre o culto imperial (Paris, 1958, reimp. 1974): Françoise Mayet sobre a cerâmica dita "de paredes finas" e, mais tarde, sobre a chamada terra sigillata; Jean Gérard Gorges sobre as villae; Alain Tranoy sobre a Galicia; Patrick le Roux sobre o papel do exército hispânico; Claude Domergue sobre a mineração; Pierre Sillières sobre as vias da Hispânia meridional. E não só na área do romano, porque André Coffyn estudou o que chamou o "Bronze Final Atlântico" e Pierre Rouillard a influência grega.

Todos esses trabalhos foram publicados na colecção em que se integra a obra alvo desta recensão.

Acrescente-se, porém, antes de entrarmos propriamente na análise do conteúdo do volume e, até, para que ele melhor se entenda, que, entre nós, depois de Conimbriga, houve o projecto de S. Cucufate e, hoje, a Missão Arqueológica Francesa em Portugal ocupa-se da zona do Sado; ou seja, depois dum itinerário urbano, passou-se a um itinerário rural e estamos agora num itinerário industrial e marítimo, para nos fazermos eco da terminologia usada na obra Itinéraires Lusitaniens (Diffusion E. de Boccard, Paris, 1997).

Há, pois, uma tradição de quase quarenta anos de investigação e não admira, portanto, que o Centre Pierre Paris possa ter investido muito em bibliografia, especializando-se precisamente na Arqueologia e na História Antiga da Península. Nesse sentido, preconizou-se que, de cinco em cinco anos, os seus investigadores, compulsando as publicações a que tinham acesso, fizessem o ponto da situação da pesquisa histórico-arqueológica, nos vários domínios em que eram peritos.

Conimbriga, 37 (1998) 267-310 
O volume em apreço reúne, como que em separata, essas "crónicas". Simplesmente, o grande mérito do trabalho reside em que se procedeu a uma unificação, agrupando as sínteses temáticas anuais em cinco grandes áreas: obras gerais, Pré-história e Proto-História, Hispânia Pré-Romana, Hispânia Romana, Hispânia Cristã e Visigótica. Inclusive as notas sofreram nova numeração.

O índice geral é suficientemente pormenorizado para que, num ápice, se encontre o que se pretende; mas, além dele, foi elaborado o índice dos autores citados (pp. 569-599) e o índice dos topónimos referidos (pp. 601-633), que são identificados por um número (há 1248 números) na carta anexa no final.

Para dar uma ideia do acervo de documentação aqui apresentada - pois que sobre cada tema se elabora uma síntese crítica, com base nos dados disponíveis - vejamos, a título de exemplo, o conteúdo do livro IV, sobre a época romana: depois de um primeiro capítulo (pp. 159-308) sobre as fontes (literárias, epigráficas, numismáticas, cerâmica e vidro, arqueologia), entretecem-se as várias "histórias" (pp. 309-432): política, militar e administrativa, religiosa - todas elas subdivididas nos temas fundamentais.

No fundo, não se trata exactamente de uma resenha bibliográfica: é, sobretudo, uma sistemática e cuidada reflexão feita por especialistas sobre as novidades que a bibliografia, ano após ano, foi apresentando. Bastará este facto para nos congratularmos com a sua publicação, tão evidente se toma a sua utilidade.

Um senão apenas, que já vai sendo normal: a incapacidade sobejamente demonstrada pelos franceses para compreenderem, duma vez por todas, que, numa lista, só os autores espanhóis se alfabetam pelo penúltimo apelido; todos os outros devem citar-se pelo último. Portanto, atenção: se quiser saber se a Dra. Maria da Conceição Lopes está referida, terá de procurar não em Lopes (como deveria ser) mas em Conceição Lopes; o Professor Armando Coelho Ferreira da Silva vem em... Coelho Ferreira da Silva (!); Jeannette Ulrica Smit Nolen, em Smit Nolen; Nelson Correia Borges, em Correia Borges; e assim por diante.

Registe-se, finalmente, com agrado, a capa escolhida: um pormenor das prateleiras da biblioteca do Centre, com as revistas peninsulares devidamente encadernadas. Na verdade, ainda hoje, o Centre Pierre Paris (agora designado AUSONIUS - Institut de Recherche sur l'Antiquité et le Moyen-Âge) dispõe de urna das bibliotecas mais bem apetrechadas sobre a Arqueologia e a História Antiga peninsulares e um estágio nas suas instalações constitui oportunidade ímpar de investigação.

JOSÉ D'ENCARNAÇÂO 